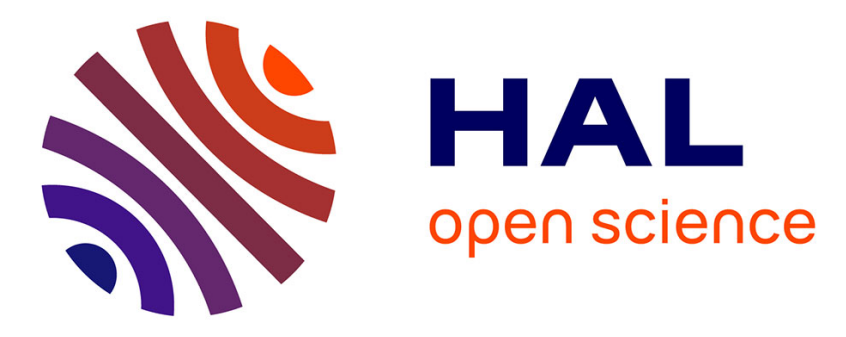

\title{
Luminescence Behavior of Protonated Methoxy-Substituted Diazine Derivatives: Towards White Light Emission
}

Sylvain Achelle, Julián Rodríguez-López, Claudine Katan, Françoise Robin-Le Guen

\section{To cite this version:}

Sylvain Achelle, Julián Rodríguez-López, Claudine Katan, Françoise Robin-Le Guen. Luminescence Behavior of Protonated Methoxy-Substituted Diazine Derivatives: Towards White Light Emission. Journal of Physical Chemistry C, 2016, 120 (47), pp.26986-26995. 10.1021/acs.jpcc.6b08401 . hal01395855

HAL Id: hal-01395855

https://hal-univ-rennes1.archives-ouvertes.fr/hal-01395855

Submitted on 14 Dec 2016

HAL is a multi-disciplinary open access archive for the deposit and dissemination of scientific research documents, whether they are published or not. The documents may come from teaching and research institutions in France or abroad, or from public or private research centers.
L'archive ouverte pluridisciplinaire HAL, est destinée au dépôt et à la diffusion de documents scientifiques de niveau recherche, publiés ou non, émanant des établissements d'enseignement et de recherche français ou étrangers, des laboratoires publics ou privés. 


\title{
Luminescence Behavior of Protonated Methoxy-Substituted Diazine Derivatives: Towards White Light Emission
}

Sylvain Achelle, ${ }^{\mathrm{ab}}$ Julián Rodríguez-López, ${ }^{* \mathrm{~b}}$ Claudine Katan ${ }^{\mathrm{c}}$ and Françoise Robin-le Guen ${ }^{\mathrm{a}}$

${ }^{a}$ Institut des Sciences Chimiques de Rennes UMR 6226, CNRS, IUT de Lannion, Université de Rennes 1, rue Edouard Branly, BP 30219, 22302 Lannion Cedex, France. E-mail: sylvain.achelle@univ-rennes1.fr; Tel: +33296469448

${ }^{b}$ Facultad de Ciencias y Tecnologías Químicas, Universidad de Castilla-La Mancha, 13071

Ciudad Real, Spain.E-mail: julian.rodriguez@uclm.es; Tel: + 34926295300

${ }^{c}$ Institut des Sciences Chimiques de Rennes, UMR 6226, CNRS, Université de Rennes 1, 35042 Rennes, France.

Corresponding author:*E-mail: sylvain.achelle@univ-rennes1.fr; julian.rodriguez@uclm.es

\begin{abstract}
White light emitting diodes (WOLEDs) are an efficient alternative to conventional lighting sources. Nevertheless, approaches to obtain WOLEDs still require complex processes that lead to high costs. In this sense, the use of a single emitting material that can take two forms of complementary emitting colors has emerged as a new strategy for the fabrication of WOLEDs. In this paper we describe the luminescent behavior upon protonation of a series of D- $\pi$-A push-pull molecules based on a methoxyphenyl or methoxynaphthyl donor unit and a diazine acceptor unit with different $\pi$-bridges. The effect of protonation on the emission properties depends on the nature of the diazine ring. The addition of trifluoroacetic acid (TFA) to pyrazine and quinoxaline derivatives led to quenching of the fluorescence whereas pyrimidine derivatives remained luminescent after protonation, which prompted a color change in the emission due to the appearance of a new red-shifted band in the spectra. These results were rationalized with the help of TD-TFT calculations. White photoluminescence could be obtained in solution by the controlled protonation of some pyrimidines, which resulted in the formation of an orange emissive acidified form. This phenomenon opens up the possibility of exploiting these materials for the fabrication of WOLEDs.
\end{abstract}




\section{INTRODUCTION}

During the past two decades there has been great interest in the fabrication of new devices for white light emission. Indeed, in context of reduced energy consumption, the development of new high efficiency and low-consumption lighting devices is a key aspect. In 1994, Kido and co-workers reported the first white organic light emitting diode (WOLED). ${ }^{1,2}$ Nowadays, WOLEDs provide a considerably more efficient alternative to conventional incandescent light bulbs and even to fluorescent tubes. ${ }^{3}$ A good warm white OLED should emit light with CIE (Commission International de l'Eclairage) coordinates close to $(0.33,0.33)$.

White light can be obtained by a combination of primary red, green and blue emission and by mixing any other complementary color pair. ${ }^{4}$ WOLEDs can be prepared by different techniques. ${ }^{5}$ Typically, a host material is doped with a mixture of different lumiphores to form a single emitting layer. ${ }^{6,7}$ Alternatively, in multilayer WOLEDs each color emitter is set in individual layers to produce the white light. ${ }^{8,9}$ Unfortunately, these approaches often require complex production processes that lead to high costs. In some recent studies, however, a new strategy has been employed that consists of integrating only one emitting material with two forms of complementary colors, such as monomer/excimer, ${ }^{10-12}$ neutral/(de)protonated ${ }^{13-16}$ or free/complexed ligand. ${ }^{17}$

Diazines are six-membered aromatic compounds that contain two nitrogen atoms. Three different structures can be distinguished according to the relative positions of the nitrogen atoms: pyridazine (1,2-diazine), pyrimidine (1,3-diazine) and pyrazine (1,4-diazine). Diazines, due to their highly $\pi$-deficient character, can be used as the electron-withdrawing part in $\pi$ conjugated push-pull structures. A significant intramolecular charge transfer (ICT) into the scaffold of the molecule can induce luminescence. An important library of fluorescent diazine derivatives has been described recently. ${ }^{18-28}$ In general, the emission of these chromophores is highly sensitive to external stimuli such as polarity, ${ }^{29-36} \mathrm{pH}^{13,31-36}$ or the presence of various 
metal cations. ${ }^{37-38}$ The protonation of diazine push-pull derivatives frequently induces a red shift of both the absorption and emission maxima. This fact can be explained by the protonation of the diazine ring, which reinforces its electron-withdrawing character and enhances the ICT into the molecule. The emission is also partially or completely quenched upon protonation, particularly with amino-substituted derivatives. ${ }^{34-36}$ Nevertheless, the presence of weaker electron-donating groups occasionally results in a moderate quenching or even an enhancement of the fluorescence intensity. ${ }^{39-40}$ The fluorescence quantum yields of these compounds are mostly low, but the extension of the $\pi$-conjugated backbone leads to a significant enhancement of the fluorescence intensity without altering the solubility properties of the chromophores. $^{34-35,41}$

In a recent communication we described in detail the emission of methoxynaphthyl-substituted pyrimidine 1 (Chart 1) with different amounts of trifluoroacetic acid (TFA). ${ }^{42}$ When the neutral and protonated forms were present in the appropriate ratio, intense white emission was observed both in solution and in thin films. The aim of the work described here was to study the luminescence behavior upon protonation of twelve diazine chromophores with the structural specifications required for intense emission of both their neutral and protonated forms (Chart 1). The main objective was to understand the results obtained in terms of structure-property relationships. TD-DFT calculations were carried out in an effort to evaluate the behavior observed experimentally for the different diazine fragments. 
<smiles>COc1ccc2cc(C=Cc3cc(/C=C/c4ccc5cc(OC)ccc5c4)ncn3)ccc2c1</smiles><smiles>COc1ccc2cc(/C=C/c3cccnn3)ccc2c1</smiles><smiles>COc1ccc2cc(/C=C/c3ccncn3)ccc2c1</smiles><smiles>COc1ccc2cc(/C=C/c3cnc4ccccc4n3)ccc2c1</smiles><smiles>COc1ccc2cc(/C=C/c3cnccn3)ccc2c1</smiles><smiles>COc1ccc(-c2ccc(/C=C/c3ccncn3)cc2)cc1</smiles><smiles>COc1ccc(-c2ccc(/C=C/c3cnc4ccccc4n3)cc2)cc1</smiles><smiles>COc1ccc(-c2ccc(/C=C/c3ccncn3)s2)cc1</smiles><smiles>COc1ccc(C#Cc2ccc(/C=C/c3ccncn3)cc2)cc1</smiles><smiles>COc1ccc(C#Cc2ccc(/C=C/c3cnc4ccccc4n3)cc2)cc1</smiles><smiles>COc1ccc2cc(-c3cc(-c4ccc5cc(OC)ccc5c4)ncn3)ccc2c1</smiles>

Chart 1.

\section{EXPERIMENTAL SECTION}

2.1. Materials. In air- and moisture-sensitive reactions all glassware was flame-dried and cooled under nitrogen. NMR spectra were acquired at room temperature on a Bruker AC-300 spectrometer. Chemical shifts are given in parts per million relative to TMS $\left({ }^{1} \mathrm{H}, 0.0 \mathrm{ppm}\right)$ and $\mathrm{CDCl}_{3}\left({ }^{13} \mathrm{C}, 77.0 \mathrm{ppm}\right)$. High resolution mass analyses were performed at the "Centre Regional de Mesures Physiques de l'Ouest" (CRMPO, University of Rennes 1) using a Bruker 
micrOTOF-Q II apparatus. UV/vis and fluorescence spectra were recorded using standard $1 \mathrm{~cm}$ quartz cells on a Jasco V-530 spectrophotometer and a Jasco FP-750 spectrofluorimeter, respectively. Fluorescence spectra are uncorrected. Compounds were excited at their absorption maxima (band of lowest energy) to record the emission spectra; however, different wavelengths were used to determine fluorescence quantum yields $\left(\Phi_{F}\right)$ in cases where compounds and standards absorbed significantly. The $\Phi_{F}$ values were calculated using two different standards, quinine sulfate in $0.1 \mathrm{M} \mathrm{H}_{2} \mathrm{SO}_{4}$ and 9,10-diphenylanthracene in cyclohexane. All solutions were measured with optical densities below 0.1 . Stokes shifts were calculated considering the lowest energetic absorption band. Acidic impurities in $\mathrm{CH}_{2} \mathrm{Cl}_{2}$ and $\mathrm{CDCl}_{3}$ were removed by treatment with anhydrous $\mathrm{K}_{2} \mathrm{CO}_{3}$. Compounds $\mathbf{1},{ }^{35} \mathbf{6}-\mathbf{7}^{34}$ and $\mathbf{9 - 1 1 ^ { 4 1 }}$ were synthesized according to reported procedures.

2.2. Computational Methods. Density functional theory (DFT) and time-dependent (TD) DFT approaches were employed, as implemented in the Gaussian 09 package. ${ }^{43}$ Ground state geometry optimizations were performed at the DFT level of theory using the $\omega \mathrm{B} 97 \mathrm{XD}^{44}$ exchange correlation functional and the $6-31 \mathrm{G}$ basis set. The same functional and basis set were used to compute the electronically excited state (ES) structure at the TD-DFT level (relative to absorption) and for ES geometry optimization (conducted at least for root $=1$ and root $=2$ ) as well as subsequent transition energies and oscillator strength relative to emission. $\omega \mathrm{B} 97 \mathrm{XD}$ is a hybrid functional that includes a full Hartree-Fock exchange at long-range interelectronic distance. As such, the use of this functional should avoid the occurrence of low-lying spurious charge transfer states $^{45}$ in the excited state structure. ${ }^{46,47}$ See the Supporting Information for details.

2.3. General Procedures for the Synthesis of Arylvinyldiazines. Method A. A stirred mixture of the corresponding methyldiazine $(3 \mathrm{mmol})$ and the appropriate aldehyde $(3 \mathrm{mmol})$ in aqueous sodium hydroxide $(5 \mathrm{M}, 30 \mathrm{~mL})$ containing Aliquat $336(130 \mathrm{mg}, 0.3 \mathrm{mmol})$ was 
heated under reflux for $2 \mathrm{~h}$ (15 h for quinoxalines). After cooling, the precipitate was filtered off, washed with water, and purified as indicated. Method B. The methyldiazine ( $5 \mathrm{mmol})$ and the aldehyde $(5 \mathrm{mmol})$ were dissolved in DMSO $(3 \mathrm{~mL})$. Powdered KOH $(1.1 \mathrm{~g}, 20.0 \mathrm{mmol})$ was added and the reaction mixture was stirred at room temperature for $8 \mathrm{~h}$. The mixture was then poured into $75 \mathrm{~mL}$ of water. The resulting precipitate was filtered off, washed with water $(2 \times 50 \mathrm{~mL})$, and purified as indicated.

2.3.1. (E)-4-[2-(6-Methoxynaphthalen-2-yl)vinyl]pyrimidine (2). Method A. Cream solid. Purified by crystallization from a mixture of $\mathrm{CH}_{2} \mathrm{Cl}_{2} / n$-heptane: $515 \mathrm{mg}$. Yield $65 \%$. Mp $157-$ $158{ }^{\circ} \mathrm{C} .{ }^{1} \mathrm{H}$ NMR $\left(300 \mathrm{MHz}, \mathrm{CDCl}_{3}\right) \delta 3.96(\mathrm{~s}, 3 \mathrm{H}), 7.19-7.10(\mathrm{~m}, 3 \mathrm{H}), 7.34\left(\mathrm{dd}, 1 \mathrm{H}, J_{1}=1.5\right.$ $\mathrm{Hz}$ and $\left.J_{2}=5.4 \mathrm{~Hz}\right), 7.78-7.75(\mathrm{~m}, 3 \mathrm{H}), 7.92(\mathrm{~s}, 1 \mathrm{H}), 8.02(\mathrm{~d}, 1 \mathrm{H}, J=16.2 \mathrm{~Hz}), 8.67(\mathrm{~d}, 1 \mathrm{H}, J$ $=5.4 \mathrm{~Hz}), 9.17(\mathrm{~s}, 1 \mathrm{H}) .{ }^{13} \mathrm{C} \mathrm{NMR}$ and JMOD $\left(75 \mathrm{MHz}, \mathrm{CDCl}_{3}\right) \delta 162.5(\mathrm{C}), 158.9(\mathrm{CH}), 158.6$ (C), $157.3(\mathrm{CH}), 137.8(\mathrm{CH}), 135.3(\mathrm{C}), 131.0(\mathrm{C}), 130.0(\mathrm{CH}), 128.93(\mathrm{CH}), 128.87(\mathrm{C}), 127.5$ $(\mathrm{CH}), 124.7(\mathrm{CH}), 124.2(\mathrm{CH}), 119.4(\mathrm{CH}), 118.5(\mathrm{CH}), 106.0(\mathrm{CH}), 55.4\left(\mathrm{CH}_{3}\right)$. HRMS (ESI/ASAP): $m / z$ calcd for $\mathrm{C}_{18} \mathrm{H}_{15} \mathrm{~N}_{2} \mathrm{O}[\mathrm{M}+\mathrm{H}]^{+} 263.1179$, found 263.1175 .

\subsection{2. (E)-3-[2-(6-Methoxynaphthalen-2-yl)vinyl]pyridazine (3). Method B. Cream solid.} Purified by column chromatography $\left(\mathrm{SiO}_{2}\right.$, EtOAc/petroleum ether 1:1): $360 \mathrm{mg}$. Yield 45\%. Mp $193-195{ }^{\circ} \mathrm{C}$ (dec.). ${ }^{1} \mathrm{H}$ NMR $\left(300 \mathrm{MHz}, \mathrm{CDCl}_{3}\right) \delta 3.93$ (s, 3H), 7.18-7.13 (m, H), 7.45$7.38(\mathrm{~m}, 2 \mathrm{H}), 7.63\left(\mathrm{dd}, 1 \mathrm{H}, J_{l}=1.2 \mathrm{~Hz}\right.$ and $\left.J_{2}=8.7 \mathrm{~Hz}\right), 7.88-7.74(\mathrm{~m}, 5 \mathrm{H}), 9.04\left(\mathrm{dd}, 1 \mathrm{H}, J_{l}=\right.$ $1.2 \mathrm{~Hz}$ and $\left.J_{2}=4.8 \mathrm{~Hz}\right) .{ }^{13} \mathrm{C}$ NMR and JMOD (75 MHz, $\left.\mathrm{CDCl}_{3}\right) \delta 158.5(\mathrm{C}), 158.4(\mathrm{C}), 149.5$ $(\mathrm{CH}), 135.4(\mathrm{CH}), 135.0(\mathrm{C}), 131.4(\mathrm{C}), 129.9(\mathrm{CH}), 128.9(\mathrm{C}), 128.2(\mathrm{CH}), 127.5(\mathrm{CH}), 126.4$ $(\mathrm{CH}), 124.3(\mathrm{CH}), 124.1(\mathrm{CH}), 123.8(\mathrm{CH}), 119.3(\mathrm{CH}), 106.0(\mathrm{CH}), 55.4\left(\mathrm{CH}_{3}\right)$. HRMS (ESI/ASAP): $m / z$ calcd for $\mathrm{C}_{18} \mathrm{H}_{15} \mathrm{~N}_{2} \mathrm{O}[\mathrm{M}+\mathrm{H}]^{+} 263.1179$, found 263.1176.

2.3.3. (E)-2-[2-(6-Methoxynaphthalen-2-yl)vinyl]quinoxaline (4). Method A. Pale yellow solid. Purified by column chromatography $\left(\mathrm{SiO}_{2}\right.$, EtOAc/petroleum ether 1:1): $545 \mathrm{mg}$. Yield 57\%. 
Mp 150-151 ${ }^{\circ} \mathrm{C} .{ }^{1} \mathrm{H}$ NMR (300 MHz, $\left.\mathrm{CDCl}_{3}\right) \delta 3.95$ (s, 3H), 7.20-7.16 (m, 2H), 7.45 (d, 1H, J $=16.5 \mathrm{~Hz}), 7.85-7.71(\mathrm{~m}, 5 \mathrm{H}), 8.03-7.97(\mathrm{~m}, 2 \mathrm{H}), 8.10-8.07(\mathrm{~m}, 2 \mathrm{H}), 9.08(\mathrm{~s}, 1 \mathrm{H}) .{ }^{13} \mathrm{C} \mathrm{NMR}$ and JMOD (75 MHz, $\left.\mathrm{CDCl}_{3}\right) \delta 150.9(\mathrm{C}), 144.5(\mathrm{CH}), 142.5(\mathrm{C}), 141.5(\mathrm{C}), 136.6(\mathrm{CH}), 135.1$ (C), $131.4(\mathrm{C}), 130.2(\mathrm{CH}), 129.9(\mathrm{CH}), 129.2(2 \times \mathrm{CH}), 129.1(\mathrm{C}), 128.9(\mathrm{CH}), 128.5(\mathrm{CH})$, $127.5(\mathrm{CH}), 124.5(\mathrm{CH}), 124.1(\mathrm{CH}), 119.3(\mathrm{CH}), 106.0(\mathrm{CH}), 55.3\left(\mathrm{CH}_{3}\right)$. HRMS (ESI/ASAP): $m / z$ calcd for $\mathrm{C}_{21} \mathrm{H}_{17} \mathrm{~N}_{2} \mathrm{O}[\mathrm{M}+\mathrm{H}]^{+} 313.1335$, found 313.1331 .

2.3.4. (E)-2-[2-(6-Methoxynaphthalen-2-yl)vinyl]pyrazine (5). Method B. Cream solid. Purified by column chromatography $\left(\mathrm{SiO}_{2}\right.$, EtOAc/petroleum ether 1:1): $554 \mathrm{mg}$. Yield 70\%. Mp 152$153{ }^{\circ} \mathrm{C} .{ }^{1} \mathrm{H}$ NMR $\left(300 \mathrm{MHz}, \mathrm{CDCl}_{3}\right) \delta 3.93$ (s, 3H), 7.26-7.14 (m, 3H), 7.77-7.75 (m, 3H), $7.90-7.85(\mathrm{~m}, 2 \mathrm{H}), 8.39(\mathrm{~d}, 1 \mathrm{H}, J=2.1 \mathrm{~Hz}), 8.55(\mathrm{~d}, 1 \mathrm{H}, J=2.1 \mathrm{~Hz}), 8.66(\mathrm{~s}, 1 \mathrm{H}) .{ }^{13} \mathrm{C} \mathrm{NMR}$ and JMOD (75 MHz, $\left.\mathrm{CDCl}_{3}\right) \delta 158.4(\mathrm{C}), 151.5(\mathrm{C}), 144.3(\mathrm{CH}), 143.7(\mathrm{CH}), 142.5(\mathrm{CH})$, $135.4(\mathrm{CH}), 135.0(\mathrm{C}), 131.5(\mathrm{C}), 129.9(\mathrm{CH}), 128.9(\mathrm{CH}), 128.2(\mathrm{C}), 127.4(\mathrm{CH}), 124.1(\mathrm{CH})$, $123.3(\mathrm{CH}), 119.3(\mathrm{CH}), 106.0(\mathrm{CH}), 55.4\left(\mathrm{CH}_{3}\right)$. HRMS (ESI/ASAP): $\mathrm{m} / \mathrm{z}$ calcd for $\mathrm{C}_{18} \mathrm{H}_{15} \mathrm{~N}_{2} \mathrm{O}[\mathrm{M}+\mathrm{H}]^{+}$263.1179, found 263.1181.

2.3.5. (E)-4-\{2-[5-(4-Methoxyphenyl)thiophen-2-yl]vinyl\}pyrimidine (8). A stirred mixture of (E)-4-[2-(5-bromothiophen-2-yl)vinyl]pyrimidine ${ }^{41} \quad(267 \quad \mathrm{mg}, \quad 1.0 \quad \mathrm{mmol}), \quad p$ methoxyphenylboronic acid (304 mg, $2 \mathrm{mmol}), \mathrm{Pd}\left(\mathrm{PPh}_{3}\right)_{4}(58 \mathrm{mg}, 0.05 \mathrm{mmol})$, aqueous $1 \mathrm{M}$ sodium carbonate $(2 \mathrm{mmol}, 2 \mathrm{~mL})$ and ethanol $(2 \mathrm{~mL})$ in degassed toluene $(20 \mathrm{~mL})$ was heated under nitrogen for $15 \mathrm{~h}$. The reaction mixture was cooled, filtered, dissolved in a mixture of EtOAc and water $(1: 1,50 \mathrm{~mL})$ and the organic layer was separated. The aqueous layer was extracted with EtOAc $(2 \times 25 \mathrm{~mL})$. The combined organic extracts were dried with $\mathrm{MgSO}_{4}$ and the solvents were evaporated. The crude product was purified by column chromatography $\left(\mathrm{SiO}_{2}, \mathrm{EtOAc} /\right.$ petroleum ether 1:1) to give $260 \mathrm{mg}$ of a yellow solid. Yield $88 \%$. Mp 157-158 ${ }^{\circ} \mathrm{C} .{ }^{1} \mathrm{H}$ NMR $\left(300 \mathrm{MHz}, \mathrm{CDCl}_{3}\right) \delta 3.85(\mathrm{~s}, 3 \mathrm{H}), 6.78(\mathrm{~d}, 1 \mathrm{H}, J=15.6 \mathrm{~Hz}), 6.93(\mathrm{~d}, 2 \mathrm{H}, J=8.7$ $\mathrm{Hz}), 7.16(\mathrm{~d}, 1 \mathrm{H}, J=3.9 \mathrm{~Hz}), 7.20(\mathrm{~d}, 1 \mathrm{H}, J=3.9 \mathrm{~Hz}), 7.20(\mathrm{~d}, 1 \mathrm{H}, J=1.2 \mathrm{~Hz}), 7.55(\mathrm{~d}, 2 \mathrm{H}, J$ 
$=8.7 \mathrm{~Hz}), 7.99(\mathrm{~d}, 1 \mathrm{H}, J=15.6 \mathrm{~Hz}), 8.63(\mathrm{~d}, 1 \mathrm{H}, J=1.2 \mathrm{~Hz}), 9.12(\mathrm{~s}, 1 \mathrm{H}) .{ }^{13} \mathrm{C} \mathrm{NMR}$ and JMOD (75 MHz, $\left.\mathrm{CDCl}_{3}\right) \delta 162.0(\mathrm{C}), 159.8(\mathrm{C}), 158.8(\mathrm{CH}), 157.2(\mathrm{CH}), 146.4(\mathrm{C}), 139.3(\mathrm{C})$, $131.3(\mathrm{CH}), 130.5(\mathrm{CH}), 127.2(\mathrm{CH}), 126.6(\mathrm{C}), 123.7(\mathrm{CH}), 122.9(\mathrm{CH}), 118.5(\mathrm{CH}), 114.5$ $(\mathrm{CH}), 55.4\left(\mathrm{CH}_{3}\right)$. HRMS (ESI/ASAP): $m / z$ calcd for $\mathrm{C}_{17} \mathrm{H}_{15} \mathrm{~N}_{2} \mathrm{OS}[\mathrm{M}+\mathrm{H}]^{+}$295.0900, found 295.0900.

2.3.6. 4,6-Bis(6-methoxynaphthalen-2-yl)pyrimidine (12). A stirred mixture of 4,6dichloropyrimidine (149 mg, $1.0 \mathrm{mmol})$, 6-methoxy-2-naphthaleneboronic acid (606 mg, 3 mmol), $\mathrm{Pd}\left(\mathrm{PPh}_{3}\right)_{4}(116 \mathrm{mg}, 0.1 \mathrm{mmol})$, aqueous $1 \mathrm{M}$ sodium carbonate $(3 \mathrm{mmol}, 3 \mathrm{~mL})$ and ethanol $(3 \mathrm{~mL})$ in degassed toluene $(25 \mathrm{~mL})$ was heated under nitrogen for $40 \mathrm{~h}$. The reaction mixture was cooled, filtered to eliminate the black palladium, and diluted with a mixture of EtOAc and water $(1: 1,50 \mathrm{~mL})$. The organic layer was separated and the aqueous layer was extracted with EtOAc $(2 \times 25 \mathrm{~mL})$. The combined organic extracts were dried with $\mathrm{MgSO}_{4}$ and the solvents were evaporated. The crude product was purified by column chromatography $\left(\mathrm{SiO}_{2}\right.$, EtOAc/petroleum ether 3:7) followed by crystallization from a mixture of $\mathrm{CH}_{2} \mathrm{Cl}_{2} / n$ heptane to give $301 \mathrm{mg}$ of a cream solid. Yield 78\%. Mp 194-196 ${ }^{\circ} \mathrm{C} .{ }^{1} \mathrm{H}$ NMR $(300 \mathrm{MHz}$, $\left.\mathrm{CDCl}_{3}\right) \delta 3.97(\mathrm{~s}, 6 \mathrm{H}), 7.27-7.21(\mathrm{~m}, 4 \mathrm{H}), 7.94-7.89(\mathrm{~m}, 4 \mathrm{H}), 8.25\left(\mathrm{dd}, 2 \mathrm{H}, J_{1}=8.7 \mathrm{~Hz}, J_{1}=\right.$ $1.5 \mathrm{~Hz}), 8.32(\mathrm{~s}, 1 \mathrm{H}), 8.65(\mathrm{~s}, 2 \mathrm{H}), 9.37(\mathrm{~s}, 1 \mathrm{H}) .{ }^{13} \mathrm{C}$ NMR and JMOD $\left(75 \mathrm{MHz}, \mathrm{CDCl}_{3}\right) \delta$ $164.6(\mathrm{C}), 159.2(\mathrm{CH}), 159.0(\mathrm{C}), 136.1(\mathrm{C}), 132.2(\mathrm{C}), 130.6(\mathrm{CH}), 128.8(\mathrm{C}), 127.6(\mathrm{CH})$, $127.3(\mathrm{CH}), 124.5(\mathrm{CH}), 119.6(\mathrm{CH}), 112.4(\mathrm{CH}), 105.8(\mathrm{CH}), 55.4\left(\mathrm{CH}_{3}\right)$. HRMS (ESI/ASAP): $m / z$ calcd for $\mathrm{C}_{26} \mathrm{H}_{21} \mathrm{~N}_{2} \mathrm{O}_{2}[\mathrm{M}+\mathrm{H}]^{+}$393.1597, found 393.1599. 


\section{RESULTS AND DISCUSSION}

3.1. Preparation of Diazine Derivatives. Methoxynaphthylvinyldiazine derivatives 2-5 were obtained by Knoevenagel condensation of 6-methoxy-2-naphthaldehyde with the appropriate methyldiazine derivative (Scheme 1). Pyrimidine and quinoxaline derivatives 2 and 4 were easily obtained in moderate yields using boiling aqueous $5 \mathrm{M} \mathrm{NaOH}$ in the presence of Aliquat 336 as a phase-transfer catalyst. Pyridazine and pyrazine derivatives $\mathbf{3}$ and $\mathbf{5}$ required a stronger base due to the lower acidity of the hydrogen atoms of the methyl group. Dimsyl potassium (potassium hydroxide in DMSO) at room temperature proved to be efficient to obtain these compounds in moderate yields.
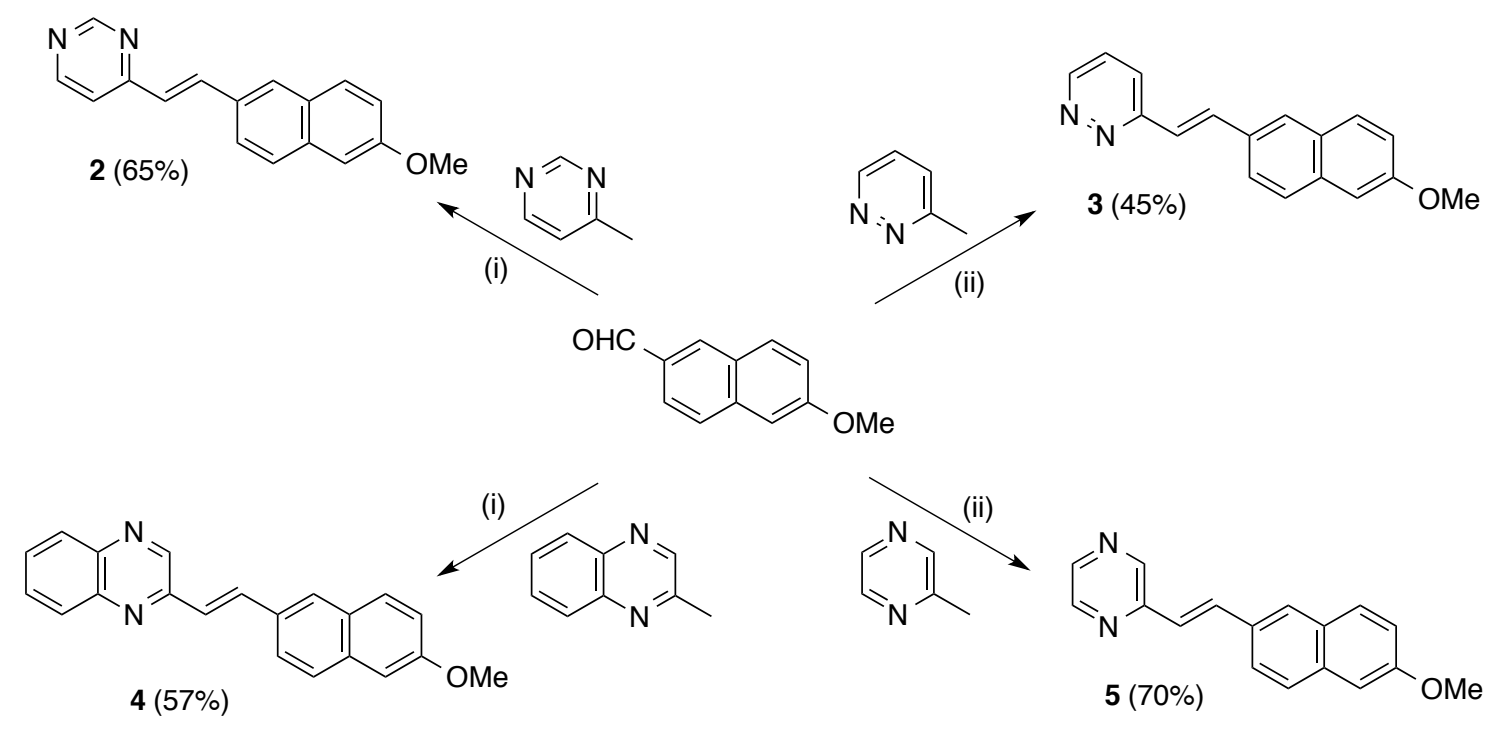

Scheme 1. Synthesis of compounds 2-5. Reagents and conditions: (i) $5 \mathrm{M} \mathrm{NaOH}$ aq., Aliquat 336, $\Delta, 2$ h (15 h for 4); (ii) KOH, DMSO, rt, 8 h.

Pyrimidines $\mathbf{8}$ and $\mathbf{1 2}$ were obtained in good yield by palladium-catalyzed Suzuki cross coupling reaction of 4-[2-(5-bromothiophen-2-yl)vinyl]pyrimidine ${ }^{41}$ or 4,6-dichloropyrimidine, respectively, and the corresponding boronic acid (Schemes 2 and 3). 

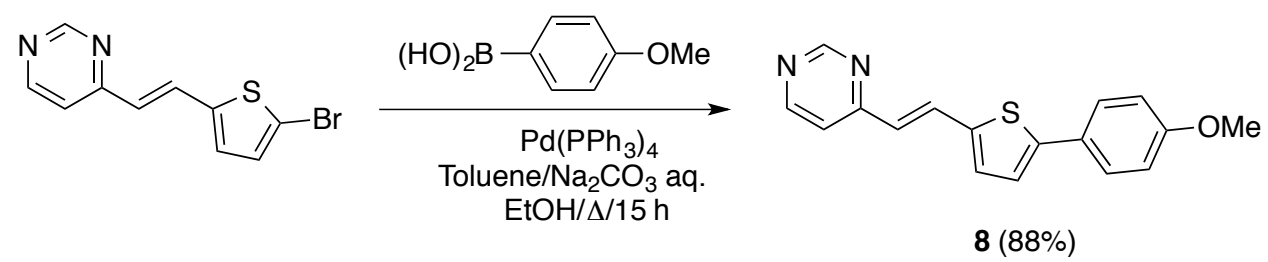

Scheme 2. Synthesis of compound $\mathbf{8}$.

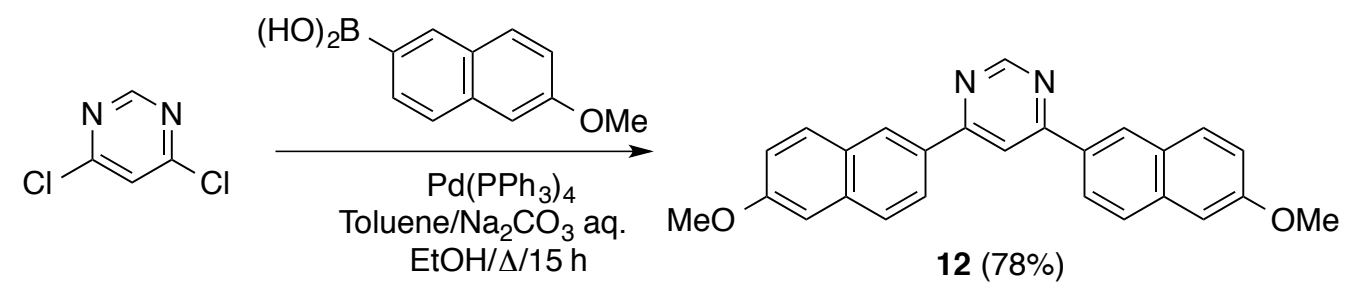

Scheme 3. Synthesis of compound 12.

3.2. UV-vis and Fluorescence Spectroscopy. The UV-Vis and photoluminescence (PL) spectroscopic data for diazine derivatives 1-12, measured in $\mathrm{CH}_{2} \mathrm{Cl}_{2}$ at $25{ }^{\circ} \mathrm{C}$, are summarized in Table 1 (see also Figures S1 and S2 in the Supporting Information for spectra of all compounds). The analyses were carried out using low concentration solutions $\left(0.9-2.0 \times 10^{-5}\right.$ M). Self-absorption effects were not observed under these conditions. All vinyl compounds proved to be photostable and $E$ to $Z$ isomerization was not observed under the experimental conditions employed in this work.

All compounds showed absorption maxima in the UV region, in the range $\lambda_{\max } 335-390 \mathrm{~nm}$, usually accompanied by one or two bands at higher energy. The compounds exhibited blue or green luminescence except for pyridazine derivative 3. Comparison of compounds $\mathbf{1}$ and $\mathbf{2}$ showed that the disubstitution of the pyrimidine ring led to a red shift in both the absorption and emission maxima and this is associated with a dramatic increase in the fluorescence quantum yield. The suppression of the vinylene linkers (compound $\mathbf{1 2}$ vs. 1) resulted in a significantly blue shifted absorption and emission, as well as in a higher fluorescence quantum yield (0.90). The quinoxaline derivatives 4, 7 and 11 (and less significantly the pyrazine 
derivative 5) showed red-shifted absorption and emission bands and increased fluorescence quantum yields in comparison with their pyrimidine analogs 2, 6 and 10, respectively. Analogous red shifts were caused by the replacement of a phenyl ring by a thienyl ring in the $\pi$ conjugated bridge (compounds $\mathbf{8}$ and $\mathbf{9}$ ), although this change was associated with a significant decrease in the fluorescence quantum yield. This fact might be related to the low luminescence of thienylenevinylene derivatives due to the stabilization of triplet excited states. ${ }^{48-50}$

Table 1. UV/Vis and photoluminescence (PL) data in $\mathrm{CH}_{2} \mathrm{Cl}_{2}$ solution.

\begin{tabular}{clccc}
\hline Compd & \multicolumn{1}{c}{$\begin{array}{c}\text { UV/vis } \lambda_{\max }, \mathrm{nm} \\
\left(\varepsilon, \mathrm{mM}^{-1} \cdot \mathrm{cm}^{-1}\right)\end{array}$} & $\begin{array}{c}\text { PL } \\
\lambda_{\max }, \mathrm{nm}\end{array}$ & $\Phi_{F}{ }^{a}$ & $\begin{array}{c}\text { Stokes shift } \\
\mathrm{cm}^{-1}\end{array}$ \\
\hline $\mathbf{1}$ & $263(26.5), 283(27.1), 380(39.1)$ & 470 & 0.37 & 5039 \\
$\mathbf{2}$ & $280(11.7), 346(22.4)$ & 436 & 0.03 & 5966 \\
$\mathbf{4}$ & $277(25.7), 335(33.5)$ & - & - & - \\
$\mathbf{5}$ & $265(24.2), 284(26.0), 383(28.9)$ & 485 & 0.48 & 5491 \\
$\mathbf{6}$ & $346(33.2)$ & 440 & 0.26 & 5682 \\
$\mathbf{7}$ & $296(20.4), 379(29.9)$ & 447 & 0.14 & 6530 \\
$\mathbf{8}$ & $273(9.4), 390(36.7)$ & 485 & 0.42 & 5767 \\
$\mathbf{9}$ & $383(36.1)$ & 500 & 0.01 & 5641 \\
$\mathbf{1 0}$ & $285(11.4), 355(28.5)$ & 489 & 0.04 & 5660 \\
$\mathbf{1 1}$ & $302(17.3), 383(30.6)$ & 460 & 0.51 & 6429 \\
$\mathbf{1 2}$ & $252(52.0), 267(55.8), 337(38.0)$ & 413 & 0.90 & 5461 \\
\hline
\end{tabular}

${ }^{a}$ Fluorescence quantum yield $( \pm 10 \%)$ determined relative to those of quinine sulfate in 0.1 $\mathrm{M} \mathrm{H}_{2} \mathrm{SO}_{4}\left(\Phi_{F}=0.54\right.$, excited at $\left.346 \mathrm{~nm}\right)$ and 9,10 -diphenylanthracene in cyclohexane $\left(\Phi_{F}\right.$ $=0.90$, excited at $393 \mathrm{~nm}$ ) as standards.

The effect of the protonation of compounds 1, 2, and 4-12 with TFA was studied. As an example, the changes observed in the UV-vis spectra of $\mathbf{4}$ upon addition of TFA are illustrated 
in Figure 1. The spectra show the progressive attenuation of the charge transfer absorption band for the neutral compound on increasing the concentration of acid, whereas a new red-shifted band corresponding to the protonated species appeared. This bathochromic shift is not surprising given the expected enhancement of the ICT into the molecule due to the increase in the electron-withdrawing character of the diazine ring due to protonation. All compounds exhibited similar behavior to 4 (Supporting Information, Figures S3-S12). It should be noted that due to the low basicity of the diazine derivatives, a large excess of TFA was required in all cases to observe the protonated species alone.

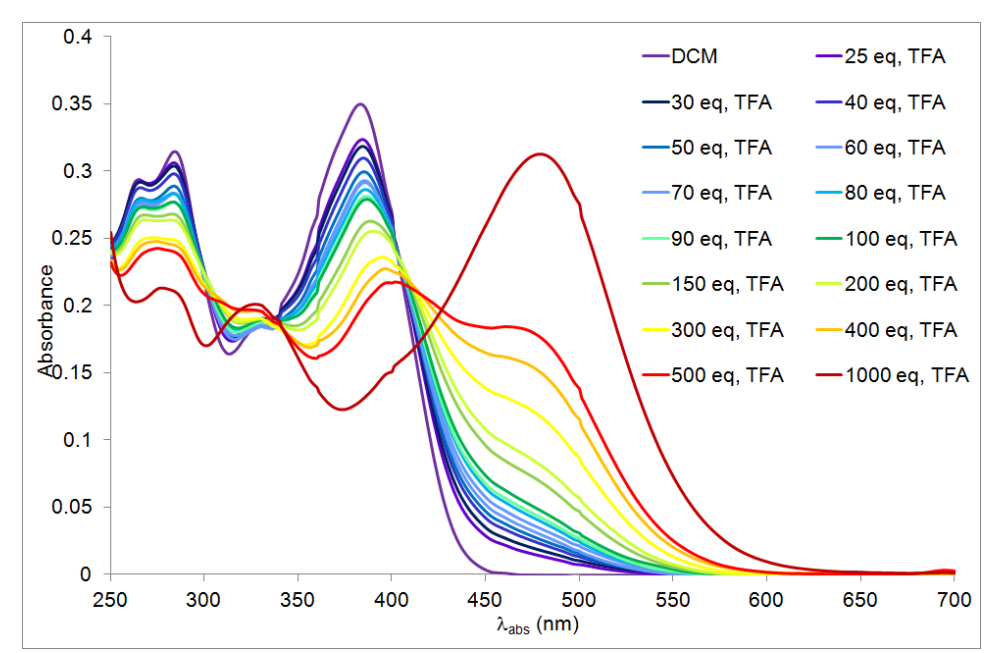

Figure 1. Changes in the absorption spectra of a dichloromethane (DCM) solution of 4 upon addition of TFA (25 to 1000 equivalents).

As far as the emission is concerned, the effect of protonation depends on the nature of the diazine ring. For pyrazine and quinoxaline derivatives, as illustrated in Figure 2 for compound 5, the progressive addition of acid caused a steady decrease in the fluorescence and ultimately led to total quenching. Nevertheless, the pyrimidine derivatives remained luminescent after protonation. As shown in Figure 3 for compound 10, the addition of TFA led to a decrease in the emission band intensity and a new red-shifted band appeared for the protonated form, the 
intensity of which was enhanced due to an intermolecular Förster resonance energy transfer (FRET). Indeed, this form acts as the energy acceptor whereas the neutral form acts as the energy donor (the absorption band of the protonated form partially overlaps the emission band of the neutral form). The progressive addition of acid prompted a color change from blue to green in the emission of compound $\mathbf{2}$ (Figure 4). In contrast, the pyrizadine derivative $\mathbf{3}$ did not retain luminescence after protonation.

It is worth noting that in both the absorption and emission spectra, isosbestic and isoemissive points were observed for low concentrations of acid, respectively. Nevertheless, these points disappeared when the concentration of acid increased. The second ionization constant for diazine derivatives is very low $\left(\mathrm{pK}_{\mathrm{a}}=-5.78\right.$ for pyrazine, -6.3 for pyrimidine and -7.1 for pyridazine $)^{51}$ and, therefore, a second protonation at the remaining $\mathrm{N}$-center is not conceivable with TFA $\left(\mathrm{pK}_{\mathrm{a}}=0.3\right)$. The disappearance of both the isosbestic and isoemissive points can be attributed to a significant change in polarity.

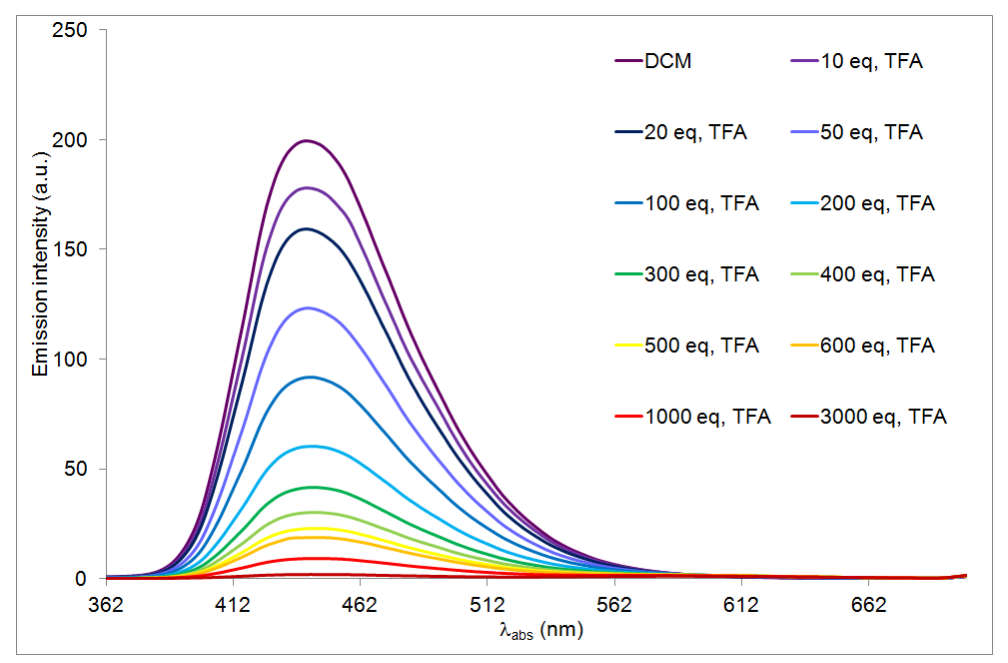

Figure 2. Changes in the emission spectra of a dichloromethane (DCM) solution of $\mathbf{5}$ upon addition of TFA (10 to 3000 equivalents), $\lambda_{\mathrm{exc}}=352 \mathrm{~nm}$. 


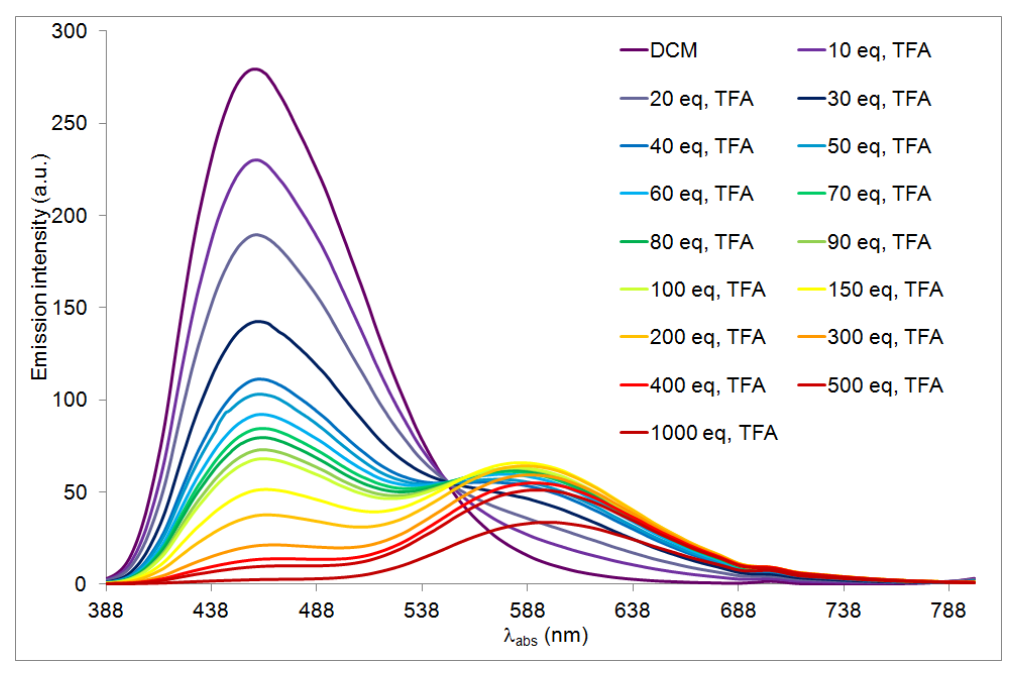

Figure 3. Changes in the emission spectra of a dichloromethane (DCM) solution of $\mathbf{1 0}$ upon addition of TFA (10 to 1000 equivalents), $\lambda_{\mathrm{exc}}=355 \mathrm{~nm}$.

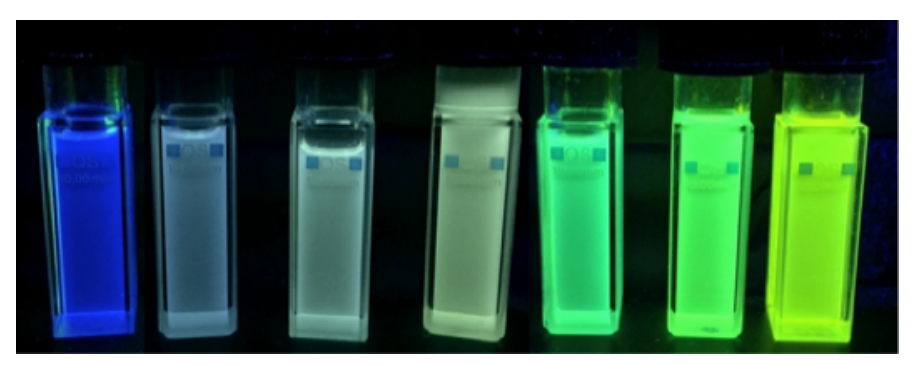

Figure 4. Changes in the color of a solution of $2\left(c=1.6 \times 10^{-5} \mathrm{M}\right.$ in $\left.\mathrm{CH}_{2} \mathrm{Cl}_{2}\right)$ with increasing amounts of TFA (from left to right). Photographs were taken in the dark upon irradiation with a hand-held UV lamp $\left(\lambda_{\mathrm{em}}=366 \mathrm{~nm}\right)$.

3.3. Theoretical Calculations. In an effort to visualize the molecular geometries, protonation sites, electronic structures, and optical properties of the molecules, computational studies involving DFT and TD-DFT calculations using the $\omega \mathrm{B} 97 \mathrm{XD}^{44}$ exchange correlation functional and the 6-31G basis set were performed. As mentioned above, $E$ to $Z$ isomerization was not observed under the analysis conditions. Thus, theoretical calculations were made only on $E$ isomers. Compounds 2-5 were taken to be representative of the series on considering different conformations by varying the dihedral angles $\phi_{1}$ and $\phi_{2}$ between the double bond and the 
diazine and naphthalene ring, respectively (Chart 1). Accurate state-specific corrections within TD-DFT are not yet possible to investigate emission of solvated chromophores and, as a consequence, all calculations were conducted in vacuum.

Table 2. Optimized ground (GS) and excited state (ES) geometries computed for neutral and protonated forms that lead to the lowest Gibbs free energy. The most favorable protonation site is indicated in parentheses.

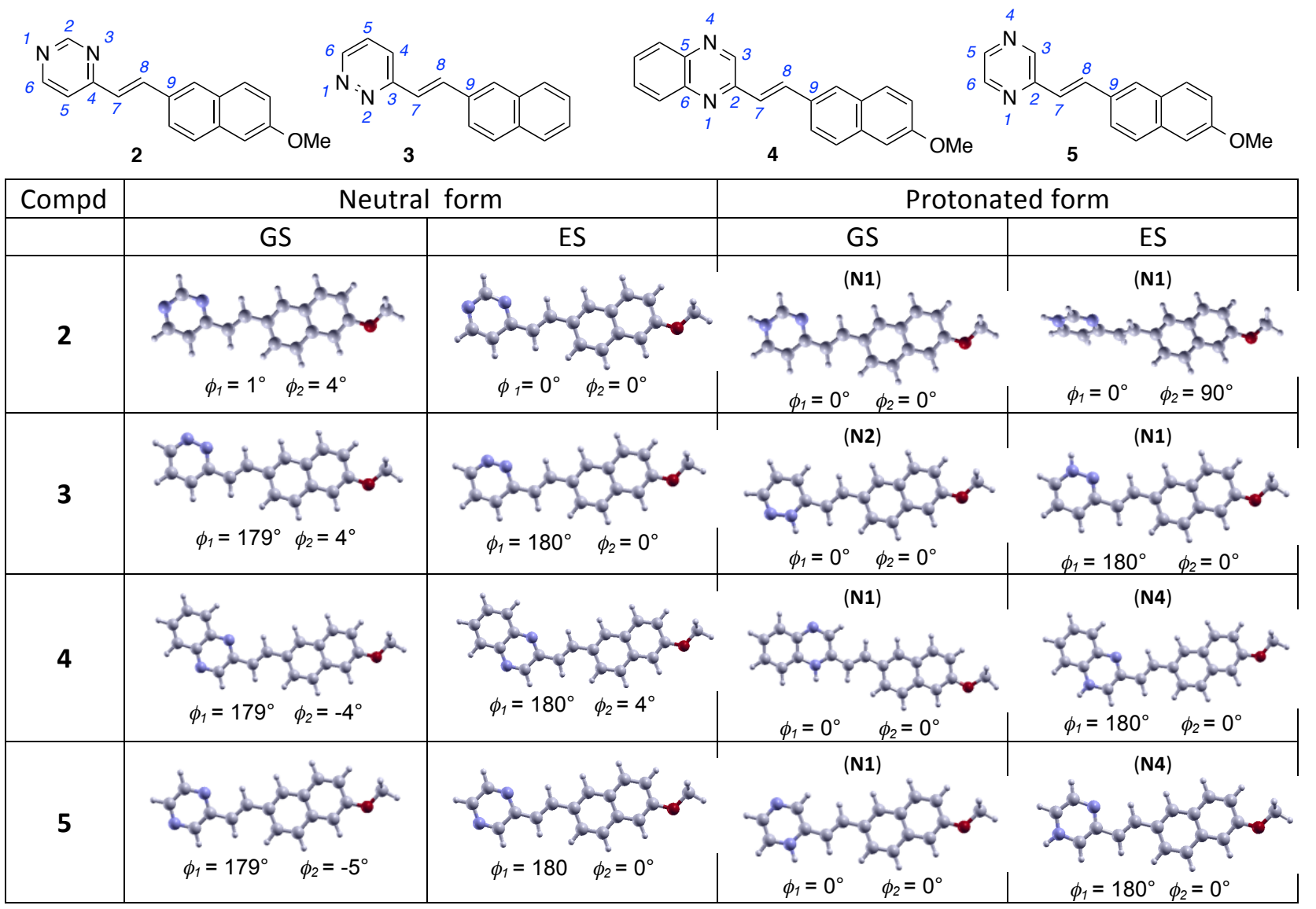

Both for neutral and protonated molecules, the ground state optimized geometries depended very little on the dihedral angles $\phi_{1}$ and $\phi_{2}$ when they were changed by $180^{\circ}$. These changes led to four different conformers with comparable Gibbs free energies $(G)$, which varied by only ca. $1 \mathrm{kcal} / \mathrm{mol}$, and this finding supports the possible coexistence of several conformers at room temperature. The corresponding data for the conformations with the lowest $G$ values are summarized in Table 2 (see also Table S1 in the Supporting Information for additional data). Ground state geometries of neutral compounds were found but they were not completely 
planar, with out of plane twist angles of less than $20^{\circ}$ and sizeable bond length alternations (BLA) in the vinyl unit. Planarization occurs upon protonation, with fully planar structures for the lowest $G$ values (Table 2), as well as a significant reduction in the BLA on the vinyl moiety and the expected changes on the diazine ring (Table S1). This would in turn improve the conjugation along the molecular backbone and influence the optical properties (vide supra). The most favorable site for protonation in the ground state was found at N1 for compound $\mathbf{2}$. In contrast, protonation occurs on the nitrogen closest to the vinyl moiety for compounds $\mathbf{3}-\mathbf{5}$. Protonation on the other nitrogen increased $G$ by $3-6 \mathrm{kcal} / \mathrm{mol}$. Such modest values computed for isolated molecules indicate the possible coexistence of different species in solution.

Excited state geometry optimization also led to a few minima on the potential energy surface (Table 2, see also Table S3 in the Supporting Information). Overall, neutral species undergo full planarization except for compound 4 , which remains slightly tilted around $\phi_{2}$. The BLA on the vinyl unit reduces in the excited state and this change is more marked when it corresponds to a bright state (Table S3). Investigation of the excited state geometries of protonated compounds was more involved and led to the identification of low-lying twisted intramolecular charge transfer (TICT) states, $^{52}$ again with the exception of compound 4 (Table S3). Interestingly, with the exception of compound $\mathbf{2}$, the position of protonation that led to the lowest $G$ value was interchanged between the ground and the relaxed excited state (Table 2). Thus, on the basis of our gas phase calculations, in all cases protonation is predicted to be favored on the nitrogen atom farthest from the vinyl moiety. Depending on the nature of the excited state of interest, the vinyl unit may or may not undergo an increase in the BLA or the expected $\mathrm{C}-\mathrm{C}$ elongation as a consequence of the TICT (Table S3). It is worth noting that these results do not provide information on whether such conformational changes are barrierless and an investigation of the overall reaction pathways would be required to reveal if this process is kinetically and thermodynamically favorable. 
To investigate the optical properties of the neutral and protonated forms, we computed the first few singlet excited states $\left(\mathrm{S}_{1}\right.$ to $\left.\mathrm{S}_{\mathrm{n}}\right)$ for absorption and emission considering the optimized ground and excited state geometries, respectively. Regarding with the absorption properties of the neutral forms, apart from compound 2 , the computed lowest lying excited state $S_{1}$ is not a bright one, i.e., $\mathrm{S}_{1}$ does not bear a significant oscillator strength, and these are $\mathrm{S}_{3}$ for $\mathbf{3}$ and $\mathrm{S}_{2}$ for 4 and 5 (Supporting Information, Table S2). The corresponding computed transition energies are consistent with experimental band positions in the UV/Vis spectra and they reveal a red shift along the series: $\lambda_{\text {abs }}(3)<\lambda_{\text {abs }}(2)<\lambda_{\text {abs }}(5)<\lambda_{\text {abs }}(4)$. All transitions mainly involve electronic redistribution from the HOMO to the LUMO. The HOMO consists of a $\pi$ orbital located on the methoxynaphthylvinyl unit and the LUMO is a $\pi^{*}$ orbital mainly located on the diazine ring with delocalization towards the vinyl moiety (see Figure 5 for compound $\mathbf{2}$ and Supporting Information, Table S1). This situation affords sizeable oscillator strengths (Table S2) for all four investigated molecules and these are consistent with experimental observations.
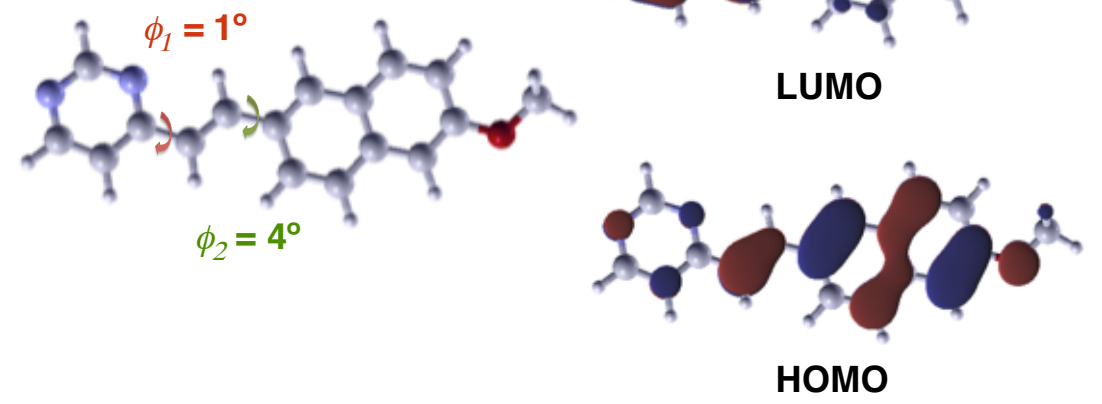

Figure 5. Optimized structure and frontier orbitals of 2.

As far as the emission is concerned, in a finding that is consistent with the absence of fluorescence measured for $\mathbf{3}$, all excited state geometry optimizations for this compound in its neutral form led to a low lying electronic transition $(c a .1 .9 \mathrm{eV})$ with vanishing oscillator 
strength (Supporting Information, Table S4) due to $n-\pi^{*}$ character that mainly involves the HOMO and LUMO (Supporting Information, Tables S3 and S5). For the other three neutral molecules we found several relaxed excited states that have comparable $G$ values, the lowest involving HOMO-1 and a LUMO with $n-\pi^{*}$ character (Tables S4 and S5). However, calculations in vacuum predict possible competition with a bright excited state with $\pi-\pi^{*}$ character, comparable to that relative to the first absorption band (HOMO-LUMO). This leads to sizeable emission, with fluorescence quantum yields that depend both on the population of bright and dark excited states and competing non-radiative deactivation. These aspects were not investigated in this work. Meanwhile, the emission bands retain the systematic red shift observed for absorption, namely $\lambda_{\mathrm{em}}(2)<\lambda_{\mathrm{em}}(\mathbf{5})<\boldsymbol{\lambda}_{\mathrm{em}}(\mathbf{4})$.

Upon protonation, the computed optical properties of diazine derivatives $\mathbf{2}-\mathbf{5}$ relative to absorption all show comparable features: the lowest excitation has a $\pi-\pi^{*}$ character with significant contribution from the HOMO and LUMO (Supporting Information, Tables S1 and S3). This species has significant oscillator strength and undergoes a systematic red shift of more than $1 \mathrm{eV}$ when compared to its neutral analog while maintaining the respective band positions along the series (Table S2). Interestingly, the main change visible in the orbitals is on the vinyl portion, which is consistent with the decrease in the BLA. Unfortunately, partial protonation in the experiments prevented a more detailed comparison between the computed and experimental results.

In a similar way to the excited state structure computed for the ground state geometry, that corresponding to the lowest lying excitation relative to fluorescence mainly involves HOMOLUMO electronic redistribution in all four compounds investigated theoretically (Supporting Information, Tables S3 and S6). Protonated pyridazine derivative 3 is predicted to remain nonfluorescent as vanishing overlap occurs between the HOMO located on the 
methoxynaphthylvinyl moiety and the LUMO centered on the diazine ring, both for the lowest lying planar excited state geometry and for the TICT one (Table S4).

The investigation of the relaxed excited state of protonated pyrimidine derivative $\mathbf{2}$ was computationally more complicated. The only instance in which a negative frequency was not reached was for the TICT state that has vanishing oscillator strength. Bright states, such as the one illustrated in Table S6 (Supporting Information), are a possible explanation for the fluorescence signal observed experimentally in all pyrimidine derivatives. For both the quinoxaline and pyrazine derivatives $\mathbf{4}$ and $\mathbf{5}$, the lowest lying relaxed excited state retained about $10 \%$ of the oscillator strength as compared to the value computed for absorption. Meanwhile, the emission is considerably red shifted to the near-IR region (Table S4) where non-radiative decays are well known to be more efficient. ${ }^{53,54}$ Moreover, given that the bright excited state for compound 4 is predicted to be destabilized by more than $11 \mathrm{kcal} / \mathrm{mol}$ in gas phase, it is likely that such non-radiative channels are the main reason for the fluorescence quenching in all of the quinoxaline derivatives. The situation is different for chromophores $\mathbf{5}$, for which TICT states were found within a few $\mathrm{kcal} / \mathrm{mol}$. Thus, these TICT states may either contribute to fluorescence quenching upon protonation of pyrazine derivatives or may be fully responsible for quenching.

3.4. White Light Luminescence. The chromacity coordinates of pyrimidine derivatives $\mathbf{1 , 2 , 6}$, 8-10 and 12 in their neutral and protonated forms are listed in Table 3 along with the chromacity coordinates for mixtures of both forms in the appropriate ratio to approach white light emission. As observed previously for compound $\mathbf{1},{ }^{42}$ the addition of 50 equivalents of TFA gave CIE coordinates of $(0.30,0.35)$ and these are very close to those of pure white light emission $(0.33,0.33)$. Biphenylene derivatives $\mathbf{6}$ and $\mathbf{1 0}$ also exhibited white emission under UV irradiation when the neutral and protonated forms were combined in precise proportions. In a similar way to $\mathbf{1}$, non-protonated and fully-protonated solutions appeared blue and orange, 
respectively (Figure 6). Perfect CIE coordinates of $(0.33,0.33)$ were obtained for $\mathbf{1 0}$, a compound that showed a noteworthy fluorescence quantum yield of 0.51 (see Table 1). Unfortunately, it was not possible to achieve white emission with compounds 2, 8, 9 and 12 .

Table 3. CIE coordinates for pyrimidine derivatives 1, 2, 6, 8-10 and 12 in $\mathrm{CH}_{2} \mathrm{Cl}_{2}$ solution $\left(c=0.9-2.0 \times 10^{-5} \mathrm{M}\right)$.

\begin{tabular}{|c|c|c|c|}
\hline \multirow[b]{2}{*}{ Compd } & \multicolumn{3}{|c|}{ Chromacity coordinates $(\mathrm{x}, \mathrm{y})$} \\
\hline & Neutral form & Protonated form & $\begin{array}{c}\text { Mixture of neutral and } \\
\text { protonated forms }\end{array}$ \\
\hline 1 & $(0.15,0.21)$ & $(0.53,0.46)$ & $(0.30,0.35)^{a}$ \\
\hline 2 & $(0.15,0.09)$ & $(0.36,0.55)$ & $(0.27,0.43)^{b}$ \\
\hline 6 & $(0.15,0.15)$ & $(0.45,0.50)$ & $(0.32,0.36)^{c}$ \\
\hline 8 & $(0.20,0.40)$ & $(0.52,0.46)$ & $(0.36,0.45)^{d}$ \\
\hline 9 & $(0.18,0.37)$ & $(0.53,0.45)$ & $(0.32,0.41)^{e}$ \\
\hline 10 & $(0.16,0.19)$ & $(0.51,0.45)$ & $(0.33,0.33)^{f}$ \\
\hline 12 & $(0.16,0.05)$ & $(0.34,0.54)$ & $(0.27,0.39)^{g}$ \\
\hline
\end{tabular}



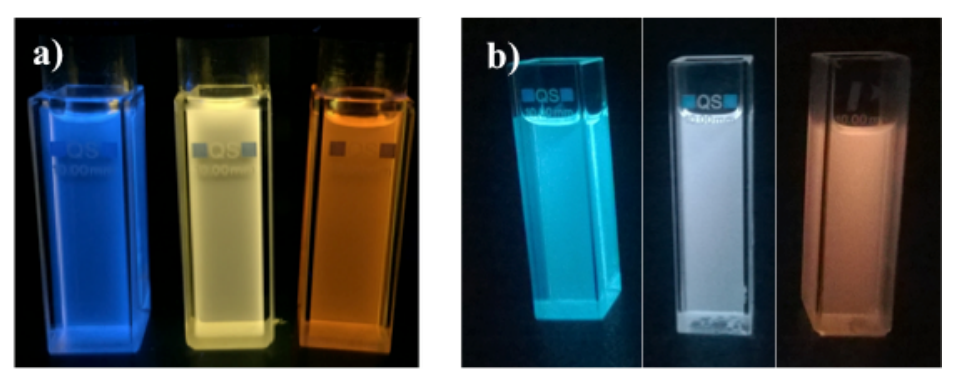

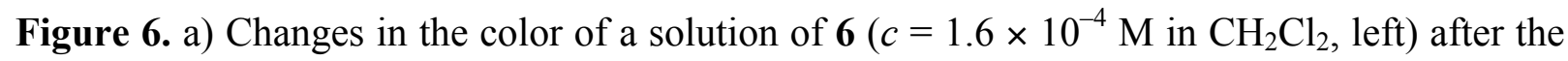
addition of 10 equivalents (middle) and 1000 equivalents (right) of TFA. b) Changes in the color of a solution of $\mathbf{1 0}\left(c=1.2 \times 10^{-5} \mathrm{M}\right.$ in $\mathrm{CH}_{2} \mathrm{Cl}_{2}$, left $)$ after the addition of 100 equivalents (middle) and 1000 equivalents (right) of TFA. Photographs were taken in the dark upon irradiation with a hand-held UV lamp $\left(\lambda_{\mathrm{em}}=366 \mathrm{~nm}\right)$.

\section{CONCLUSIONS}

The luminescence behavior of a series of $D-\pi-A$ push-pull diazine derivatives has been studied. In these compounds either a methoxyphenyl or methoxynaphthyl donor unit was connected to the diazine acceptor ring through different $\pi$-bridges. Some of the compounds were prepared and characterized for the first time by following well-established, straightforward methodologies. All compounds showed absorption bands in the UV region and the emission of blue or green light upon irradiation (except for the pyridazine derivative 3 ). The materials could be easily protonated with TFA at the nitrogen atoms of the diazine ring. Protonation of pyrazine and quinoxaline derivatives always led to quenching of the fluorescence. In contrast, pyrimidine derivatives remained luminescent with the appearance of a new red-shifted band in the spectra of the protonated form. Rationalization of the experimental results in terms of structure-property relationships was achieved by TD-TFT calculations. The controlled protonation of some blue-emitting pyrimidine derivatives led to white photoluminescence by formation of an orange emissive acidified form. This phenomenon should enable the 
development of WOLEDs based on push-pull pyrimidine derivatives after suitable design of the molecules.

\section{SUPPORTING INFORMATION}

The Supporting Information is available free of charge on the ACS Publications website at DOI: 10.1021/acs.jpcc.XXXX. Computational details and additional results including structural data of the optimized geometries and computed optical properties relative to absorption and emission (Tables S1-S4), molecular orbitals relative to emission for neutral and protonated forms (Tables S5-S6), UV/Vis and fluorescence spectra for all compounds (Figures S1-S2), changes in the absorption and emission spectra upon addition of TFA (Figures S3-S20), and ${ }^{1} \mathrm{H}$ NMR and JMOD spectra for all new compounds (Figures S21-S26) (PDF).

\section{AUTHOR INFORMATION}

\section{Corresponding Authors}

*(S.A.) E-mail: sylvain.achelle@univ-rennes1.fr

*(J.R.-L.) E-mail: julian.rodriguez@uclm.es

\section{Notes}

The authors declare no competing financial interest.

\section{ACKNOWLEDGEMENTS}

C.K. would like to thank Karine Costuas for useful discussions and acknowledges the HPC resources of CINES and of IDRIS under the allocations 2016-[x2016080649] made by GENCI (Grand Equipment National de Calcul Intensif). S.A. would like to thank Guillaume Chenais and Yoann Lalaizon, students at IUT Lannion, for preliminary syntheses. 


\section{REFERENCES}

(1) Kido, J.; Hongawa, K.; Okuyama, K.; Nagai, K. White Light-Emitting Organic Electroluminescent Devices Using the Poly( $N$-vinylcarbazole) Emitter Layer Doped with Three Fluorescent Dyes. Appl. Phys. Lett. 1994, 64, 815-817.

(2) Kido, J.; Kimura, M.; Nagai, K. Multilayer White Light-Emitting Organic Electroluminescent Device. Science 1995, 267, 1332-1334.

(3) Reineke, S.; Lindner, F.; Schwartz, G.; Seidler, N.; Walzer, K.; Lüssem, B.; Leo, K. White Organic Light-Emitting Diodes with Fluorescent Tube Efficiency. Nature 2009, 459, 234-238.

(4) Mukherjee, S.; Thilagar, P. Organic White-Light Emitting Materials. Dyes Pigm. 2014, 110, $2-27$.

(5) Gather, M. C.; Köhnen, A.; Meerholz, K. White Organic Light-Emitting Diodes. Adv. Mater. 2011, 23, 233-248.

(6) D’Andrade, B. W.; Holmes, R. J.; Forrest, S. R. Efficient Organic Electrophosphorescent White-Light-Emitting Device with a Triple Doped Emissive Layer. Adv. Mater. 2004, 16, 624628.

(7) Kim, T.-H.; Lee, H. K.; Park, O. O.; Chin, B. D.; Lee, S.-H.; Kim, J. K. White-LightEmitting Diodes Based on Iridium Complexes via Efficient Energy Transfer from a Conjugated Polymer. Adv. Funct. Mater. 2006, 16, 611-617.

(8) D’Andrade, B. W.; Thompson, M. E.; Forest, S. R. Controlling Exciton Diffusion in Multilayer White Phosphorescent Organic Light Emitting Devices. Adv. Mater. 2002, 14, 147151.

(9) Sun, Y.; Giebink, N. C.; Kanno, H.; Ma, B.; Thompson, M. E.; Forrest, S. R. Management of Singlet and Triplet Excitons for Efficient White Organic Light-Emitting Devices. Nature 2006, 440, 908-912. 
(10) Tao, S.; Zhou, Y.; Lee, C.-S.; Lee, S.-T.; Huang, D.; Zhang, X. A Triphenylamine Derivative as a Single-Emitting Component for Highly-Efficient White Electroluminescent Devices. J. Mater. Chem. 2008, 18, 3981-3984.

(11) Liu, L.; Chen, F.; Xu, B.; Dong, Y.; Zhao, Z.; Tian, W.; Ping, L. Solution-Processed White Organic Light-Emitting Diode Based on a Single-Emitting Small Molecule. Synth. Met. 2010, $160,1968-1972$.

(12) Fleetham, T.; Ecton, J.; Wang, Z.; Bakken, N.; Li, J. Single-Doped White Organic LightEmitting Device with an External Quantum Efficiency Over 20\%. Adv. Mater. 2013, 25, 25732576.

(13) Liu, D.; Zhang, Z.; Zhang, H.; Wang, Y. A Novel Approach Towards White Photoluminescence and Electroluminescence by Controlled Protonation of a Blue Fluorophore. Chem. Commun. 2013, 49, 10001-10003.

(14) Huynh, H. V.; He, X.; Baumgartner, T. Halochromic Generation of White Light Emission Using a Single Dithienophosphole Luminophore. Chem. Commun. 2013, 49, 4899-4901.

(15) Romero-Nieto, C.; Durben, S.; Kormos, I. M.; Baumgartner, T. Simple and Efficient Generation of White Light Emission from Organophosphorus Building Blocks. Adv. Funct. Mater. 2009, 19, 3625-3631.

(16) Yang, Y.; Lowry, M.; Schowalter, C. M.; Fakayode, S. O.; Escobedo, J. O.; Xu, X.; Zhang, H.; Jensen, T. J.; Fronczek, F. R.; Warner, I. M.; Strongin, R. M. An Organic White Light-Emitting Fluorophore. J. Am. Chem. Soc. 2006, 128, 14081-14092.

(17) Shiraishi, Y.; Ichimura, C.; Sumiya, S.; Hirai, T. Multicolor Fluorescence of a Styrylquinoline Dye Tuned by Metal Cations. Chem.-Eur. J. 2011, 17, 8324-8332.

(18) Achelle, S.; Baudequin, C. Recent Advances in Pyrimidine Derivatives as Luminescent, Photovoltaic and Non-Linear Optical Materials. Targets Heterocycl. Syst. 2013, 17, 1-37. 
(19) Achelle, S.; Plé, N.; Turck, A. Incorporation of Pyridazine Rings in the Structure of Functionalized $\pi$-Conjugated Materials. $R S C A d v$. 2011, 1, 364-388.

(20) Achelle, S.; Baudequin, C.; Plé, N. Luminescent Materials Incorporating Pyrazine or Quinoxaline Moieties. Dyes Pigm. 2013, 98, 575-600.

(21) Skardziute, L.; Dodonova, J.; Voitechovicius, A.; Jovaisaite, J.; Komskis, R.; Voitechoviciute, A.; Bucevicius, J.; Kazlauskas, K.; Jursenas, S.; Tumkevicius, S. Synthesis and Optical Properties of the Isomeric Pyrimidine and Carbazole Derivatives: Effects of Polar Substituents and Linking Topology. Dyes Pigm. 2015, 118, 118-128.

(22) Verbitskiy, E. V.; Schepochkin, A. V.; Makarova, N. I.; Dorogan, I. V.; Metelitsa, A. V.; Minkin, V. I.; Kozyukhin, S. A.; Emets, V. V.; Grindberg, V. A.; Chupakhin, O. N.; Rusinov; G. L.; Charushin, V. N. Synthesis, Photophysical and Redox Properties of the D- $\pi-$ A Type Pyrimidine Dyes Bearing the 9-Phenyl-9H-Carbazole Moiety. J. Fluoresc. 2015, 25, 763-775.

(23) Savel, P.; Akdas-Kilig, H.; Malval, J.-P.; Spangenberg, A.; Roisnel, T.; Fillaut, J.-L. Metal-Induced Dimensionality Tuning in a Series of Bipyrimidine-Based Ligands: A Tool to Enhance Two-Photon Absorption. J. Mater. Chem. C 2014, 2, 295-305.

(24) Lu, X.; Fan, S.; Wu, J.; Jia, X.; Wang, Z.-S.; Zhou, G. Controlling the Charge Transfer in D-A-D Chromophores Based on Pyrazine Derivatives. J. Org. Chem. 2014, 79, 6480-6489.

(25) Denneval, C.; Moldovan, O.; Baudequin, C.; Achelle, S.; Baldeck, P.; Plé, N.; Darabantu, M.; Ramondenc, Y. Synthesis and Photophysical Properties of Push-Pull Structures Incorporating Diazines as Attracting Part with a Fluorene Core. Eur. J. Org. Chem. 2013, 55915602.

(26) Chen, D.; Zhong, C.; Dong, X.; Liu, Z.; Qin, J. A New Building Block, Bis(thiophene vinyl)-Pyrimidine, for Constructing Excellent Two-Photon Absorption Materials: Synthesis, Crystal Structure and Properties. J. Mater. Chem. 2012, 10, 4343-4348. 
(27) Kato, S.-i.; Yamada, Y.; Hiyoshi, H.; Umezu, K.; Nakamura, Y. Series of CarbazolePyrimidine Conjugates: Syntheses and Electronic, Photophysical, and Electrochemical Properties. J. Org. Chem. 2015, 80, 9076-9090.

(28) Nosova, E. V.; Moshkina, T. N.; Lipunova, G. N.; Kopchuk, D. S.; Slepukhin, P. A.; Baklanova, I. V.; Charushin, V. N. Synthesis and Photophysical Studies of 2-(Thiophen-2-yl)4-(morpholin-4-yl)quinazoline Derivatives. Eur. J. Org. Chem. 2016, 2876-2881.

(29) Bagley, M. C.; Lin, Z.; Pope, S. J. A. Barium Manganate in Microwave-Assisted Oxidation Reactions: Synthesis of Solvatochromic 2,4,6-Triarylpyrimidines. Tetrahedron Lett. 2009, 50, 6818-6822.

(30) Lincker, F.; Kreher, D.; Attias, A.-J.; Do, J.; Kim, E.; Hapiot, P.; Lemaître, N.; Geffroy, B.; Ulrich, G.; Ziessel, R. Rodlike Fluorescent $\pi$-Conjugated 3,3'-Bipyridazine Ligand: Optical, Electronic, and Complexation Properties. Inorg. Chem. 2010, 49, 3991-4001.

(31) Schmitt, V.; Moschel, S.; Detert, H. Diaryldistyrylpyrazines: Solvatochromic and Acidochromic Fluorophores. Eur. J. Org. Chem. 2013, 5655-5669.

(32) Wink, C.; Detert, H. Donor-Substituted Distyrylpyrazines: Influence of Steric Congestion on UV-Vis Absorption and fluorescence. J. Phys. Org. Chem. 2013, 26, 144-150.

(33) Singh, P.; Baheti, A.; Thomas, K. R. J. Synthesis and Optical Properties of Acidochromic Amine-Substituted Benzo[a]phenazines. J. Org. Chem. 2011, 76, 6134-6145.

(34) Achelle, S.; Barsella, A.; Baudequin, C.; Caro, B.; Robin-le Guen, F. Synthesis and Photophysical Investigation of a Series of Push-Pull Arylvinyldiazine Chromophores. J. Org. Chem. 2012, 77, 4087-4096.

(35) Achelle, S.; Nouira, I.; Pfaffinger, B.; Ramondenc, Y.; Plé, N.; Rodríguez-López, J. VShaped 4,6-Bis(arylvinyl)pyrimidine Oligomers: Synthesis and Optical Properties. J. Org. Chem. 2009, 74, 3711-3717. 
(36) Achelle, S.; Rodríguez-López, J.; Robin-le Guen, F. Synthesis and Photophysical Studies of a Series of Quinazoline Chromophores. J. Org. Chem. 2014, 79, 7564-7571.

(37) Achelle, S.; Rodríguez-López, J.; Bureš, F.; Robin-le Guen, F. Dipicolylamine Styryldiazine Derivatives: Synthesis and Photophysical Studies. Dyes Pigm. 2015, 121, 305311.

(38) Hadad, C.; Achelle, S.; López-Solera, I.; García-Martínez, J. C.; Rodríguez-López, J. Metal Cation Complexation Studies of 4-Arylvinyl-2,6-di(pyridin-2-yl)pyrimidines: Effect on the Optical Properties. Dyes Pigm. 2013, 97, 230-237.

(39) Achelle, S.; Robin-le Guen, F. 2-Arylvinylpyrimidines versus 4-Arylvinylpyrimidines: Synthesis and Comparison of the Optical Properties. Tetrahedron Lett. 2013, 54, 4491-4496.

(40) Hadad, C.; Achelle, S.; García-Martínez, J. C.; Rodríguez-López, J. 4-Arylvinyl-2,6di(pyridin-2-yl)pyrimidines: Synthesis And Optical Properties. J. Org. Chem. 2011, 76, 38373845.

(41) Achelle, S.; Barsella, A.; Caro, B.; Robin-le Guen, F. Donor-Linker-Acceptor (D- $\pi-A)$ Diazine Chromophores with Extended $\pi$-Conjugated Cores: Synthesis, Photophysical and Second Order Nonlinear Optical Properties. RSC Adv. 2015, 5, 39218-39227.

(42) Achelle, S.; Rodríguez-López, J.; Cabon, N.; Robin-le Guen, F. Protonable Pyrimidine Derivative for White Light Emission. RSC Adv. 2015, 5, 107396-107399.

(43) Frisch, M. J.; Trucks, G. W.; Schlegel, H. B.; Scuseria, G. E.; Robb, M. A.; Cheeseman, J. R.; Scalmani, G.; Barone, V.; Mennucci, B.; Petersson, G. A. et al. Gaussian 09, Revision D.01, Gaussian, Inc., Wallingford CT, 2013.

(44) Chai, J.-D.; Head-Gordon, M. Long-Range Corrected Hybrid Density Functionals with Damped Atom-Atom Dispersion Corrections. Phys. Chem. Chem. Phys. 2008, 10, 6615-6620. 
(45) Magyar, R. J.; Tretiak, S. Dependence of Spurious Charge-Transfer Excited States on Orbital Exchange in TDDFT: Large Molecules and Clusters. J. Chem. Theory Comput. 2007, 3, $976-987$.

(46) Jacquemin, D.; Adamo, C. Computational Molecular Electronic Spectroscopy with TDDFT. Top. Curr. Chem. 2016, 368, 347-375.

(47) Katan, C.; Savel, P.; Wong, B. M.; Roisnel, T.; Dorcet, V.; Fillaut, J.-L.; Jacquemin, D. Absorption and Fluorescence Signatures of 1,2,3-Triazole Based Regioisomers: Challenging Compounds for TD-DFT. Phys. Chem. Chem. Phys. 2014, 16, 9064-9073.

(48) Hwang, I.-W.; Xu, Q.-H.; Soci, C.; Chen, B.; Jen, A. K.-Y.; Moses, D.; Heeger, A. J. Ultrafast Spectroscopic Study of Photoinduced Electron Transfer in an Oligo(thienylenevinylene):Fullerene Composite. Adv. Funct. Mater. 2007, 17, 563-568.

(49) Samuel, I. D. W.; Meyer, K. E.; Bradley, D. D. C.; Friend, R. H.; Murata, H.; Tsutsui, T.; Saito, S. Transient Absorption and Reflectivity Studies of Poly(2,5-thienylene vinylene). Synth. Met. 1991, 41, 1377-1380.

(50) Apperloo, J. J.; Martineau, C.; van Hal, P. A.; Roncali, J.; Janssen, R. A. J. Intra- and Intermolecular Photoinduced Energy and Electron Transfer between Oligothienylenevinylenes and N-Methylfulleropyrrolidine. J. Phys. Chem. A 2002, 106, 21-31.

(51) Dines, T. J.; MacGregor, L. D.; Rochester, C. H. The Surface Acidity of Oxides Probed by IR Spectroscopy of Adsorbed Diazines. Phys. Chem. Chem. Phys. 2001, 3, 2676-2685.

(52) Grabowski, Z. R.; Rotkiewicz, K. Structural Changes Accompanying Intramolecular Electron Transfer: Focus on Twisted Intramolecular Charge-Transfer States and Structures. Chem. Rev. 2003, 103, 3899.

(53) Sauer, M.; Hofkens, J.; Enderlein, J. Handbook of Fluorescence Spectroscopy and Imaging: From Ensemble to Single Molecules; Wiley-VCH: Weinheim, Germany, 2011. 
J. Phys. Chem. C, 2016, 120 (47), pp 26986-26995; DOI: 10.1021/acs.jpcc.6b08401

(54) Steffen, A.; Costuas, K.; Boucekkine, A.; Thibault, M.-H.; Beeby, A.; Batsanov, A. S.; Charaf-Eddin, A.; Jacquemin, D.; Halet, J.-F.; Marder, T. B. Fluorescence in Rhoda- and Iridacyclopentadienes Neglecting the Spin-Orbit Coupling of the Heavy Atom: The Ligand Dominates. Inorg. Chem. 2014, 53, 7055-7069. 
J. Phys. Chem. C, 2016, 120 (47), pp 26986-26995; DOI: 10.1021/acs.jpcc.6b08401

TABLE OF CONTENTS IMAGE

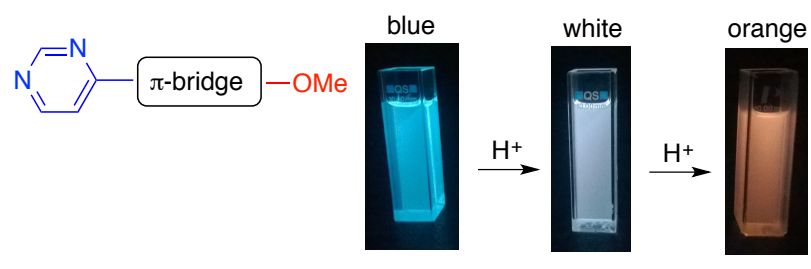

r-bridge $-\mathrm{OMe} \stackrel{\mathrm{H}^{+}}{\rightarrow} \begin{aligned} & \text { Quenching of } \\ & \text { fluorescence }\end{aligned}$ 